\title{
Waldemar Espinoza Soriano y la didáctica de la historia
}

Eduardo M. Pacheco Peña

ORCID: 0000-0002-9913-0379

Sanyorei Porras Cosme

ORCID: 0000-0001-9876-2035

Universidad Nacional Daniel Alcides Carrión

\section{Resumen}

El estudio forma parte de un análisis de los cuadernos de apuntes del joven estudiante Marino Pacheco Sandoval cuando asistió a las cátedras de Waldemar Espinoza Soriano, entre 1962 y 1966 en el pregrado de la Facultad de Educación de la Universidad Nacional del Centro del Perú. Esta fuente escrita desvela la labor educativa poco conocida del historiador en su estadía en el valle del Mantaro. Espinoza Soriano influenció con su didáctica de la historia a una pléyade de inquietos estudiosos de la Ciencias Sociales, la Historia, la Filosofía y el Folclore.

\section{Resumo}

The study is part of an analysis of the notebooks of the young student Marino Pacheco Sandoval when he attended the chairs of Waldemar Espinoza Soriano, between 1962 and 1966 in the undergraduate of the Faculty of Education of the National University of Central Peru. This written source reveals the historian's little-known educational work during his stay in the Mantaro Valley. Espinoza Soriano influenced a host of restless students of Social Sciences, History, Philosophy and Folklore with his didactics of history.

\section{Palabras clave:}

Enseñanza de la historia. Didáctica de la historia.

\section{Palavras-chave:}

Teaching of history. Didactics of history.

\section{Preámbulo}

Marino Pacheco Sandoval (Jauja, 1943-Huancayo, 2003) estudió en el Programa Académico de Educación en la Universidad Nacional del Centro del Perú. Ingresó a esa institución en 1962. El Certificado del 31 de diciembre de 1966, expedido por la Facultad de Educación, hace constar que concluyó satisfactoriamente sus estudios profesionales en la especialidad de Historia y Geografía. En 1967, por su solvencia académica lo contratan en el periodo vacacional de la Academia Oficial Pre-Universitaria de la UNCP, centro de repaso instruccional que regentaba la Federación de Estudiantes. El o3 de noviembre de aquel año, la universidad le confiere el Grado de Bachiller en Educación, especialidad de Historia y Geografía (diploma de Bachiller a nombre de la Nación $N^{\circ} 169$ del 18 de noviembre de 1967).

Pacheco Sandoval, en el pre grado le sonrió la fortuna. Tuvo la suerte de recibir por varios años las enseñanzas de un profesor extraordinario: Waldemar Espinoza Soriano. Antiguo discípulo de Raúl Porras Barrenechea y Luis E. Valcárcel. Merced a la maravillosa experiencia con aquel maestro, Marino se apasionó por la historia a pesar de sus dificultades económicas, por ello siempre le guardó respeto, admiración y afecto. Jamás fue de sus discípulos más estudiosos, pero podemos afirmar que su lealtad académica al maestro nunca cejó. 
El azar juega en ocasiones un rol determinante en la vida de las personas. El azar del destino condujo los pasos de Marino Pacheco Sandoval, adolescente jaujino de orígenes campesinos, al programa académico para la enseñanza de la Historia en la UNCP; al mismo tiempo, que el Dr. Waldemar Espinoza, se trasladaba por razones de trabajo docente de Lima a Huancayo.

\section{Waldemar Espinoza Soriano en la UNCP}

Antes de establecer domicilio fijo en Huancayo, Waldemar Espinoza Soriano regresaba de España tras realizar valiosas investigaciones históricas en el Archivo General de Indias de Sevilla (1958 a 1962), merced a una beca del Instituto de Cultura Hispánica y el Instituto de Estudios Andinos de Nueva York. Historiador disciplinado, metódico, sabio e innovador, en el Archivo de Indias descubrió, entre innumerables documentos, las "probanzas" de los curacas huancas don Felipe Guacrapáucar y don Francisco Cusichaca; estas probanzas confirmaban la alianza hispano-wanka para derrotar a los orejones cusqueños. Ese hecho cambió la visión que poseíamos del Tahuantinsuyo e incorporó a la clásica consulta de crónicas, otros folios valiosos (visitas, probanzas, testamentos, relaciones y más).

El profesor Espinoza, armado con un nuevo corpus teórico y documental, cambió la perspectiva tradicional de los estudios del mundo andino, una perspectiva que emergía desde la palabra escrita de los pueblos vencidos y silenciados por los Incas, varios de los cuales colaboraron a toda costa con los conquistadores europeos. Racionalizó información pormenorizada del ordenamiento social multidimensional y multiétnico del Tahuantinsuyo, asimismo, de la primera centuria de la dominación estatal hispana del área andina (Ecuador, Perú, Bolivia y Chile), construyendo una explicación histórica esencial sobre el Estado Inca y la instauración del virreinato del Perú en el siglo XVI. Observó el bosque y los árboles.

La visión de conjunto que científicamente hilvanó no dejó de lado la monografía especializada de las realidades locales y regionales. En esta senda regionalista redactó la encomiable Historia del Departamento de Junín (1973), obra pionera que se situó como el primer tratado historiográfico regional. En un artículo periodístico (Huarhua y Vergara, 2008) indicó que aprehendió el valor de "la erudición, la archivística, la documentación manuscrita y editada, el análisis, la crítica, la corrección en los escritos" de sus maestros Porras y Valcárcel. Residiendo en Huancayo enseñó a sus jóvenes estudiantes con la misma diligencia, erudición y fervor democrático.

Invitaron al historiador a una plaza docente en la recientemente creada Universidad Comunal del Centro, pero antes de acceder a ella defendió en la UNMSM su tesis de grado de Doctor. Una anécdota célebre narra que provisto de las fichas documentales que trajo de Sevilla, en sólo ocho días culminó y presentó la tesis doctoral titulada El Alcalde mayor en el Virreinato del Perú. Tesis que fue aprobada con excelencia en la decana de América. Así, el novel Doctor ganó la plaza en la universidad huanca.

En su condición de docente a dedicación exclusiva (de 1962 a 1975) dirigió de modo formidable la cátedra de historia. Se dice que hasta el día de hoy ningún otro maestro superó su saber ni enseñanza. Permaneció trece años en Huancayo, fijándose como meta retornar en algún momento a Lima. ¿A quién no le atrae las bondades culturales de la capital, ciudad monopolio de los centros académicos, libros, revistas, bibliotecas, archivos y eventos científicos especializados? En 1975 ganó un nombramiento en la UNMSM y partió en viaje definitivo a Lima, pero esa es otra historia que no compete al presente artículo.

Desde su posición académica en Huancayo, Espinoza Soriano impulsó la renovación de los estudios etnohistóricos. Sus libros más reconocidos (1973 y 1971) se prepararon en el Valle del 
Mantaro. Huancayo por entonces conservaba la tradicional configuración urbana de inicios del siglo XX: viejas casonas de adobe enlucidas con yeso, techos de tejas de arcilla cocida, con huertos hermoseando patios interiores en el mismo centro de la ciudad. La calle Real se modernizaba con la edificación de cines y tiendas de ventas de artefactos eléctricos, pero dominicalmente aún era escenario de la tradicional feria que emocionó a José María Arguedas.

Los otros libros que Waldemar Espinoza escribió en la ciudad incontrastable (1964-1974) y que publicó en otros tantos confines los detallamos en las referencias bibliográficas del presente. Libros que acompañaron a un centenar de memorables artículos, especializados o de divulgación, que envío a periódicos y revistas nacionales o extranjeras. Publicaciones que Marino Pacheco solo conoció en parte como alumno suyo. Hoy podemos cotejar esas publicaciones en estricto orden cronológico en el blog del mismo historiador: http://waldemarespinozasoriano.blogspot.com/.

Como se señaló líneas antes, el Dr. Waldemar Espinoza sentó las bases científicas del conocimiento de la realidad histórica regional en Junín. El balance temático de sus artículos periodísticos (de 1962 a 1976) refrendan que gran parte de sus inquietudes los centró en esta Región. Nadie antes ni ahora había escrito con tal profusión y ciencia sobre la historia de un pueblo tan distante al lugar de su nacimiento, la capital del país o a la tierra de su formación profesional. Tal vez es una característica peculiar de los científicos sociales de ascendencia cajamarquina, pues similar tarea realizó en el Cusco su paisano Horacio Villanueva Urteaga.

La máxima positivista "la historia solo puede escribirse con fuentes históricas, método heurístico, análisis e interpretación histórica, disciplina y objetividad", el notable doctor la aplicó al estudio de aquella historia regional y sus demás pesquisas. En la actualidad sus estudios sobre el orbe social, económico, político y cultural del Tahuantinsuyo prevalecen entre otras páginas memorables dedicadas a distintas épocas de la historia sudamericana andina.

\section{La innovadora didáctica de la historia}

La personalidad extraordinaria del historiador cinceló la vocación del joven Marino Pacheco por la Historia. En la UNCP. La obra monumental de Waldemar Espinoza también se extendió a la enseñanza.

En numerosas oportunidades facilitó a los estudiantes, además de su diálogo personal, los libros de su extraordinaria biblioteca. Los forjó en el hábito y entusiasmo por la lectura. Motivaba con tal abnegación y libertad a los alumnos, que ellos asumiendo plenamente su aprendizaje autónomo y sin ninguna supervisión recorrían la ciudad en búsqueda de textos especializados de la más diversas procedencias. Del mismo modo, los instruyó para coleccionar todo tipo de impresos públicos: proclamas, manifiestos, trípticos de actividades educativas y culturales, programas religiosos y políticos, afiches de festividades artísticas y académicas, tarjetas de invitación, etcétera. Cada documento colectado debía servir en algún momento como fuente histórica.

Enseñó que la curiosidad del educador de historia tiene que ser integral, un hombre con lecturas filosóficas, políticas, literarias, de ciencias básicas, estéticas y éticas. A la par, de organizadores de biblioteca especializadas, multidisciplinares y extensas en sus preocupaciones cognoscitivas.

Enseñó el arte de la investigación. Instruía a sus alumnos que al desarrollar una investigación histórica lo esencial era hacerlo en base a fuentes escritas inéditas o impresas, fuentes orales, fuentes etnográficas, evidencias materiales arquitectónicas o utensilios artesanales e industriales, evidencias iconográficas y evidencias orgánicas. Coincidiendo con el trabajo de 
Pablo Macera, quién a fines de los 60 aplicaba sus encuestas del arte rural andino en Cusco, Waldemar Espinoza registraba el arte pictórico virreinal en el valle del Mantaro.

Promovió entre los estudiantes el trabajo de campo, las excursiones y visitas de estudios. Para el caso del registro de fuentes del patrimonio monumental planteaba explorar in situ cada lugar, cotejando la información proporcionada por los documentos con la realidad. Con las crónicas en la mano, el maestro Waldemar dirigía a sus alumnos por las llactas wankas (Huarihuillca, Tunánmarka, Arwaturo, Xauxatambo, entre otros centros arqueológicos). Insistía que los estudiantes realicen levantamientos topográficos, descripciones arquitectónicas y registros visuales de los centros arqueológicos o monumentos coloniales visitados.

Adicional a esto, los conminaba a escribir informes científicos donde sistematizaban y exponían los datos descubiertos. Simeón Orellana (1973) realizó, bajo su dirección, algunos registros arqueológicos que publicó los Anales de la UNCP. Cuando Marino Pacheco en 1973, guiaba a sus alumnos de la UNCP por los pueblos antiguos del Valle del Mantaro entreviendo la vieja demarcación, por ejemplo, de los primeros solares hispanos de la primera capital del Perú en Jauja, recordaba que ya la había recorrido con su ilustre profesor. Juan Cangahuala Malpica, en su época de estudiante, editó modestas revistas de historia inspirado por su maestro historiador; revistas que son inubicables en la actualidad; sabemos por conversaciones con el historiador de San Jerónimo de Tunán en el 2004 que ahondó por influjo del Dr. Espinoza Soriano en el registro y colecta intensiva de la flora del valle del Mantaro, diferenciando los especímenes originarios de los exóticos. Desconocemos de igual forma donde se publicó tal estudio.

Espinoza Soriano en el desarrollo de su cátedra exigía a los estudiantes leer libros de historiadores por lo útiles que serían para la fundamentación científica disciplinar, las explicaciones de los hechos históricos y las anécdotas con que motivar el aprendizaje de los niños y jóvenes. Demostraba él mismo en todo instante, en cada sesión de aprendizaje, que sus propias lecturas eran oceánicas. Lo testifica una experiencia personal que le sucedió a Pacheco Sandoval: El profesor Espinoza Soriano habitualmente solicitaba del estudiante traer al aula el libro que ordenaba leer y tras hojearlo hacía preguntas puntuales sobre su contenido. No había autor ni asunto histórico que no conociera. Desde el momento que veía el texto se notaba su sabiduría excepcional. El joven Marino, visitante asiduo de librerías, encontró un libro rarísimo en una tienda de libros viejos. Este ejemplar no figuraba en los ficheros de la biblioteca de la UNCP, tampoco lo citaban las Fuentes históricas peruanas (1954) de Raúl Porras Barrenechea, que era el vademécum de consultas obligatorio. Lo leyó para los orales. En la clase fijada para el oral, Marino presentó el texto intentando sorprender al maestro, pero al final el sorprendido fue él. Waldemar conocía el texto a plenitud, sabía de sus ediciones y formatos, los cambios y adiciones en su contenido. Concluida la prueba oral que sin dudas aprobó, el maestro lo felicitó por su curiosidad y lo interrogó sobre como lo había adquirido, indicándole que en efecto aquel libro era rarísimo.

Cada asignatura recibía la misma atención. Por ejemplo, en las clases de la asignatura de Historia crítica de la Conquista, Waldemar Espinoza comenzaba enumerando y describiendo las crónicas del S. XVI, las cartas de los conquistadores, la información de méritos y servicios de los conquistadores, los cedularios del Perú hasta 1540, y la crónica de 1541 del padre Juan de Morales. Informaba que esta última fuente documental es clave para exponer los factores violentos de la conquista: las violaciones de las mujeres, los enterramientos vivos de indios, los castigos sumarios con mutilaciones e invalidez física, la calcinación a fuego vivo de cientos de indígenas, el incendio de los pueblos nativos. Luego, seguía el estudio de las fuentes bibliográficas: la Historia de la Conquista del Perú (1851) de William Prescott (un clásico de más de 150 años), el Descubrimiento y conquista del Perú (1963) de Guillermo Ballesteros Gabrois (lo más reciente y completo de la historia moderna por entonces) y La guerra de los viracochas (1963) y Manco Inca (1964) de Juan José Vega (que en esa etapa el Dr. Espinoza Soriano valoraba como 
historiografía típica). Su disertación prolija de información y ejemplos, fluía en explicaciones militares, jurídicas, psicológicas, geográficas, económicas, terminológicas y sociales.

En las sesiones de aprendizaje dialogaba con Valcárcel, Baudín, Bataillón, Vicens Vives, Ramos, Murra, Barreda, Morales Padrón, Berroa, Menéndez Pidal, etcétera, discutiendo los planteamientos teóricos y empíricos de estos autores con los suyos propios. Cieza, Garcilaso, Gómara y otros cronistas ponían la sazón con sus datos. Para que los estudiantes comprendan realidades distantes infería la información a otros contextos conocidos, así expuso que:

Entre los reinos pobrísimos de España se encontraba Castilla, era una región frígida semejante al departamento de Puno, desde el punto de vista agrario no producía nada, tan solamente existían pastos naturales parecidos al ichu. Los castellanos desde el punto de vista psíquico eran sobrios... (Pacheco Sandoval, s.f.).

Para reforzar el aprendizaje de los estudiantes huancaínos, Espinoza Soriano proporcionó la monografía Historia del Perú: Instituciones incas de Ella Dunbar Temple (2014), originalmente impreso a mimeógrafo en 1958, obra de consulta que redactó para la cátedra de Historia de las Instituciones Peruanas en la UNMSM. Este gesto de honestidad intelectual demostró que sus alumnos en Huancayo se educaron en igualdad de oportunidades que los estudiantes de historia de la UNMSM, en la capital del país. Waldemar confió en las capacidades académicas de sus pupilos, por esa razón demandaba de ellos mayor dedicación a nivel de un investigador social.

En las lecciones del historiador prevalecían las interrogantes desencadenadoras de conflictos cognoscitivos, que absolvían las dudas en la misma medida que cimentaban una sólida formación científica. Los datos inéditos de sus investigaciones en Sevilla, su extraordinario saber histórico, relucían en los temas propuestos; por ejemplo, en su lección acerca de "La realidad política del Imperio en momentos de la Conquista" hacía alusión de por qué las nacionalidades indígenas se aliaron a los españoles (Cañaris, Chachapoyas y Huancas). Espinoza Soriano al exponer cada asunto, por más intrascendente que aparentara ser, lo transformaba en una dilucidación erudita, como aquella vez que dedicó su clase a los perros de la conquista, exponiendo su importancia bélica, familiaridad con el equipo militar hispano y su eficacia en la guerra contra los incas, entre sus muchos ejemplos mencionó que "Pedro de Ursua descubre Moyobamba en 1560 llevando 800 perros..." (Pacheco Sandoval, s.f.); u otra que destinó al estudio de la fundación de ciudades virreinales, proponiendo una taxonomía novedosa, profunda y copiosa en patrones de asentamiento.

El estilo caligráfico de los apuntes de Marino Pacheco Sandoval muestra que su maestro explicaba los temas con celeridad. Los apuntes no posibilitan una lectura acompasada y legible; se nota en su cursiva la prisa, la abreviación de palabras, la esquematización apresurada de subtemas, tratando de registrar lo esencial. Espinoza Soriano no dictaba; exponía, interrogaba, dialogaba y argumentaba. Así lo refleja el Cuaderno de apuntes. El uso de la pizarra debió ser exclusivo para los títulos de los distintos campos del conocimiento y los conceptos claves. Quizá utilizó cuadros sinópticos o gráficos para concluir sus razonamientos. No lo sabemos. La geografía que se diserta es literal, no hay mapas o cartas geográficas en los apuntes. La agradable voz y disertación del maestro con seguridad despertaba la imaginación y la representación icónico-cognitiva de los alumnos. Para reforzar la información fue indispensable la consulta cartográfica de los libros especializados que citaba. En la pequeña biblioteca de Marino relucían muchos libros de cartográfica histórica.

Pacheco Sandoval conservó esos singulares "cuadernos de apuntes", que después fueron su apoyó básico al planificar y organizar sus propias lecciones de fines de los 70 en la Universidad Nacional Daniel Alcides Carrión donde asumió la cátedra de Historia. Lo atestiguan sus esquemas, guías temáticos y fichas textuales insertas entre las páginas del block estudiantil. 
La metodología de trabajo universitario que aprendió Marino Pacheco Sandoval de su querido maestro, primero lo aplicó con sus alumnos de primaria y secundaria y más tarde con sus estudiantes universitarios.

Las clases propuestas por el historiador a los estudiantes de la Facultad de Educación con mención en Historia alcanzó extraordinarios resultados. Ausubel (1976) indicaría sin dudar que logró aprendizajes significativos. Waldemar Espinoza no sólo formó a educadores con un amplio dominio de la especialidad sino también forjó investigadores sociales. Los discípulos alcanzaron las competencias necesarias que los hicieron irradiar como profesionales paradigmáticos del ámbito regional de la sierra centro del Perú. Sus nombres provocan la admiración y respeto en las regiones donde trabajaron: Simeón Orellana Valeriano (educador, historiador y folclorista huancaíno), Jaime Cerrón Palomino (educador y filósofo), Juan Cangahuala Malpica (educador e historiador regional), Marino Pacheco Sandoval (educador e historiador pasqueñista).

Hoy, 2020, que en las Facultades de Educación numerosos docentes universitarios dictan sólo una versión historiográfica lineal, leen un solo autor y un solo texto, pretendiendo que exista una única descripción y explicación de la historia, entendiendo mal la didáctica superior, creemos oportuno repasar la excepcional experiencia que llevó a cabo Waldemar Espinoza Soriano en la UNCP. El problema es que en la post modernidad han triunfado los manuales de divulgación estatal y los profesores de historia de la educación básica solo rinden pleitesía al manual del MINEDU, olvidando adquirir libros de las ciencias históricas, adicional a otros recursos educativos.

A inicios de la década del 70, Waldemar Espinoza dirigió a buen puerto la tesis de Pacheco Sandoval. Tras una férrea defensa de la misma, Marino Pacheco se tituló de Profesor de Educación Secundaria. En relación a esta cuestión otra anécdota personal de Marino Pacheco describe la calidad académica de su mentor: cada avance de su tesis recibió de Waldemar Espinoza las más severas observaciones. Los otros jurados se contentaron con suscribir el primer informe. Para alcanzar la aprobación escrita de Waldemar Espinoza el autor de la tesis rehízo cada capítulo y párrafo hasta el cansancio. La investigación tenía que justificarse con fichas, datos y argumentos. Los capítulos y temas tenían que disponerse en concordancia a un orden lógico, cronológico y geográfico. Asimismo, la composición del texto tenía que ajustarse a las normas gramaticales y semánticas. Marino absolvió cada una de las observaciones con fuentes documentales y bibliográficas, puliendo su descripción textual y edificando una narración histórica novedosa del tema. La supervisión de Espinoza Soriano garantizó un documento consistente y confiable. Pacheco Sandoval trabajó sin descanso para satisfacer el criterio calificador de su maestro. Cuando entregó su informe a la Facultad para la designación de la fecha de defensa, el documento había sufrido modificaciones esenciales.

El día fijado para la sustentación verbal de la tesis, los otros jurados entablaron una férrea discusión con su autor, procurando rebatir sus afirmaciones y evidencias. No pudieron lograrlo por los fundamentos teóricos y empíricos adquiridos por el joven investigador durante los meses que duró la revisión de la tesis. Cuando le correspondió el turno a Waldemar Espinoza, quien presidía el jurado, expresó:

La tesis del señor Pacheco la revisé durante varios meses, cada vez que observé el trabajo exigí al joven su replanteamiento; con esfuerzo y dedicación lo hizo. Hasta el día que firmé mi conformidad con el informe final, él cumplió con precisar, fundamentar y exponer mejor su investigación. Esta mañana sólo esperé la sustentación de un trabajo que con paciencia ya leí y corregí. Evalúo que la sustentación fue clara y metódica, reflejando lo hecho en la tesis. Por lo tanto, no tengo ninguna pregunta que hacerle, porque en la revisión de su estudio él respondió a todas mis inquietudes. Lo felicito por la exposición y sin esperar el juicio conjunto de los demás jurados, doy por anticipado mi veredicto de aprobado." (Testimonio personal de Pacheco Sandoval, 2003). 
En esa jornada, nadie pudo oponerse a la evaluación del historiador y aprobaron la sustentación por unanimidad. Esta anécdota sobre el actuar de Espinoza Soriano es otro ejemplo para los catedráticos que olvidan que lo más importante de una tesis no es la sustentación sino el cuidado del progreso y término de la investigación; es decir, la revisión responsable, y búsqueda incansable de mejoras en el estudio, corrigiendo y apuntalando cada argumento del tesista. La sustentación sólo es el acto protocolar donde se comunican los resultados finales.

\section{Referencias Bibliográficas.}

Ausubel, David P. (1976). Psicología educativa. Un punto de vista cognoscitivo. México: Editorial Trillas.

Ballesteros-Gaibrois, Manuel (1963) Descubrimiento y conquista del Perú. Barcelona: Salvat editores.

Dunbar Temple, Ella (2014). Instituciones. Lima: Col. Clásicos Sanmarquinos, Universidad Nacional Mayor de San Marcos. Fondo Editorial - Fundación Temple Radicati.

Espinoza, W. (1964a). Pedro de Cieza de León. En Biblioteca hombres del Perú. Tomo XII. Segunda Serie. Editorial Universo Lima.

Espinoza, W. (1964b) Biografía de Garci Diez de San Miguel, Corregidor y Visitador de Chucuito. Visita hecha a la provincia de Chucuito por Garci Diez de San Miguel en el año de 1567. Lima: Talleres Gráficos Quiroz S.A., pp. 371-417. (Trascripción paleográfica que corrió a cargo de Waldemar Espinoza).

Espinoza, W. (1967). Bolívar en Huancayo (1824). Lima: Concejo Provincial de Huancayo, Inspección de Cultura/Talleres de la Compañía de Impresiones y Publicidad S.A.

Espinoza, W. (1969) Lurinhuayla de Huacjcra: Un ayllu y un curacazgo huanca. Huancayo: Publicaciones de la Casa de la Cultura/Talleres de la Voz de Huancayo.

Espinoza, W. (1971). Los Huancas aliados de la conquista. Tres informaciones inéditas sobre la participación indígena en la conquista del Perú. 1558 - 1560 - 1561. Anales de la Universidad Nacional del Centro del Perú, Talleres Gráficos P. L. Villanueva S.A. Lima.

Espinoza, W. (1973a) Historia del Departamento de Junín. Editor Enrique Chipoco Tovar. Huancayo. Imprenta San Fernando 395 Pp.

Espinoza, W. (1973a). La destrucción del Imperio de los Incas. La rivalidad señorial y política de los curacazgos andinos. Retablo de Papel Ediciones, Lima.

Espinoza, W. (1973C). Historia del Departamento de Junín. Editor Enrique Chipoco Tovar. Huancayo: Imprenta San Fernando.

Espinoza, W. (1974). Los señoríos étnicos del valle de Condebamba y provincia de Cajabamba. Etnohistoria de las Huarancas de Llucho y Mitmas. Siglos XV - XX. Lima: Universidad Nacional del Centro del Perú/Talleres Gráficos P. L. Villanueva S.A.

Huarhua, Rody y Elver Vergara (2008). Pasado, presente y futuro o la historia trimencional. Entrevista al maestro Waldemar Espinoza Soriano. Illapa, Revista Latinoamericana de Ciencias Sociales 1 (3).

Orellana, Simeón (1973) Huacjlasmarca, un pequeño poblado huanca. Anales científicos de la Universidad Nacional del Centro del Perú, $\mathrm{N}^{\circ}$ 2, HUANCAYO

Pacheco Sandoval, Marino (1972). La resistencia inca de Vilcabamba. Tesis de Licenciatura en Educación Secundaria: Especialidad de Historia y Geografía. UNCP.

Pacheco Sandoval, Marino (s.f.). Cuaderno de apuntes. Inédito.

Porras Barrenechea, Raúl (1954). Fuentes históricas peruanas. Lima: Juan Mejía Baca y P. L. Villanueva editores.

Prescott, William H. (1851) Historia de la Conquista del Perú, con observaciones preliminares sobre la Civilización de los Incas. Madrid: Imprenta y Librería de Gaspar y Roig, Editores. En línea: file:///C:/Users/Acer/Downloads/historia-de-la-conquista-del-peru--con-observacionespreliminares-sobre-la-civilizacion-de-los-incas--por-guillermo-h-prescott.pdf

Vega, Juan José (1963) La guerra de los viracochas. Lima: Populibros peruanos.

Vega, Juan José (1964) Manco Inca, el gran rebelde. Lima: Populibros peruanos.

1 Los autores de la presente editorial fueron invitados a escribirla con la intención de rememorar la trayectoria de Waldemar Espinoza Soriano en la Universidad Nacional del Centro del Perú. 